\title{
Heat Transfer Coefficient and Flow Characteristics of Hot Steel Plate Cooling by Multiple Inclined Impinging Jets
}

\author{
Qian XIE, Bingxing WANG, ${ }^{*}$ Zhaodong WANG and Guodong WANG \\ The State Key Laboratory of Rolling and Automation, Northeastern University, Shenyang, 110819 China. \\ (Received on September 4, 2015; accepted on August 9, 2016; J-STAGE Advance published date: \\ October 27, 2016)
}

\begin{abstract}
In the hot rolled plate manufacturing process, thermo-mechanical control process (TMCP) technology is widely used to improve controlled cooling technology. A new cooling system based on inclined staggered impinging jets was developed and adopted in a commercial steel mill. This study mainly focused on the surface flow field and heat transfer coefficient of the new cooling system. The flow field was numerically studied, and a method was developed to calculate the average heat transfer coefficient. And the relationship between jet velocity and average pressure in the impinging area was investigated. The study revealed that the average pressure almost increased linearly with improving the jet velocity. Meanwhile, the average heat transfer coefficient was observed to increase with average pressure in the range of 524-2 989 Pa. However, heat transfer coefficient increased by only $8.4 \%$ with the plate moving speed of $0.7 \mathrm{~m} / \mathrm{s}$ when the average pressure increased from 1623 to $2989 \mathrm{~Pa}$. Additionally, the experimental data were useful to predict the cooling rate and microstructure of the steel product.
\end{abstract}

KEY WORDS: hot rolled plate; controlled cooling; impinging jet; heat transfer coefficient.

\section{Introduction}

Controlled cooling is an important part of thermosmechanical controlled process (TMCP) technology, which has a significant influence on the microstructure and mechanical property of hot rolled plate. Ultra-fast cooling (UFC) technology has attracted tremendous attention owing to its superior cooling ability and uniformity in cooling.

Impinging jet is the major cooling form in ultra-fast cooling, which involves multiple heat transfer regimes, such as single-phase forced convection, nucleate/transition boiling, forced convection film boiling, agglomerated pool, radiation and convection. ${ }^{1,2)}$ The primary mechanisms of the impinging jet had already been extensively studied. Several works had investigated the visible heat transfer regions (wetted region, wetting front region and dry region) of single-bunch impinging jet. ${ }^{3-6)}$ In the wetted region, the dominant heat transfer is nucleate boiling, but the bubbles are invisible in this region. In the wetting front region, the dominant heat transfer is transient boiling. And the splashed water-drop in the dry region exhibits the film boiling. The maximum heat flux is found to be in the fully wetted region by observing the movement of the wetted front and the heat transfer characteristics during the cooling process. Moreover, the wetting front velocity is influenced by both jet velocity and subcooling. Robidou and his coworkers ${ }^{7)}$ focused on the stable boiling at different surface temperatures. They obtained entire boiling curves of hot plates with different

\footnotetext{
* Corresponding author: E-mail: wbxang@126.com

DOI: http://dx.doi.org/10.2355/isijinternational.ISIJINT-2015-509
}

heating temperatures by cooling under a plane water jet, and they found a turning point during the transition from nucleate to film boiling.

However, there are also some studies that focused on the cooling process in industrial conditions. Mozumder ${ }^{8)}$ had experimentally investigated the transient heat transfer of water jet impinging on a hot rotating stainless steel cylinder with a diameter of $135 \mathrm{~mm}$. While the rotational speed was in the range of $0-60 \mathrm{rpm}$ (linear velocity $0-0.42 \mathrm{~m} / \mathrm{s}$ ). They found the higher surface velocity would lower the surface heat flux. However, this experiment was constrained by the small diameter of the steel cylinder, on which the spread water fell off rather than stayed on the surface.

In order to improve the cooling ability and uniformity in hot plate cooling, the flow condition on the plate surface still needs to be studied thoroughly. The flow field studies of a free axisymmetric impinging jet on a moving surface were performed by Gradeck et al., ${ }^{9)}$ who contrived an equation to estimate the radius of the pressure jump. Cho et al. ${ }^{10)}$ focused on the flow field of staggered arranged nozzles jet on a moving surface and utilized the Fluent software to conduct the numerical calculation. Finally, an equation to predict the height of the water pool on the surface was established. Dano et al. ${ }^{11)}$ studied the flow and heat transfer characteristics of a confined crossflow jet. They distinguished the difference between the circular nozzle and cusped ellipse nozzle. The stronger influence on the surface flow and better overall heat transfer ability was observed on cusped ellipse nozzle than on the circular nozzle.

In the industrial process, the distribution of Nusselt number $(\mathrm{Nu})$ has not yet been well studied for the dynamic 
rolling process of the plate. The uniform heat extraction by the surface flow field is crucial for controlling the product quality. The heat transfer strongly depends on the surface flow field, which is affected by nozzle arrangement, nozzle geometry flow rate, and other parameters. Obviously, the unambiguous and detailed relationship between flow field and heat transfer during the cooling process needs to be further studied.

To further understand the relationship between flow field and average heat transfer coefficient on an industrial scale, we presented a study on the average heat transfer coefficient of the flow field, which was carried out by the numerical analysis, and was driven by the UFC system under different jet velocities. Meanwhile, the average heat transfer coefficient was also calculated.

\section{Experiment}

The UFC system is being currently used in the industry, and its appearance schematic frame is shown in Fig. 1. The main components of the UFC system include liftable framework, stagger arranged nozzles and water supply system. The Fig. 2 shows the nozzles with the fixed inclination angle. The velocity of cooling water impinged on the plate surface is in the range of $5-20 \mathrm{~m} / \mathrm{s}$.

The UFC system includes 24 groups of nozzle manifolds at an interval of $0.8 \mathrm{~m}$ and the inclination angle is $80^{\circ}$. Sideblow nozzle jet located at the interval of nozzle manifolds is used to reduce the residual water and enhance the cooling efficiency. The flow rate is manipulated by an automation system and measured by the flowmeter. The plate tempera- ture is measured by LAND infrared pyrometer ( $\left.\mathrm{LSP}_{\mathrm{HD}} 21\right)$, which measuring range is $300-1000^{\circ} \mathrm{C}$ with an accuracy of $\pm 2^{\circ} \mathrm{C}$. The pyrometers are located at four positions as shown in Fig. 3. The temperature data is gathered along the length direction at an interval of $0.1 \mathrm{~s}$.

The composition of the test plate (carbon steel Q345, the density of $7800 \mathrm{~kg} / \mathrm{m}^{3}$ ) is listed in Table 1 . The length, width, and thickness of the test plate were $18742 \times 2173 \times 30 \mathrm{~mm}$ respectively, and the thickness deviation was within $5 \%$. The plate was heated to $1200^{\circ} \mathrm{C}$ in the furnace and transported to the rolling mill. The target

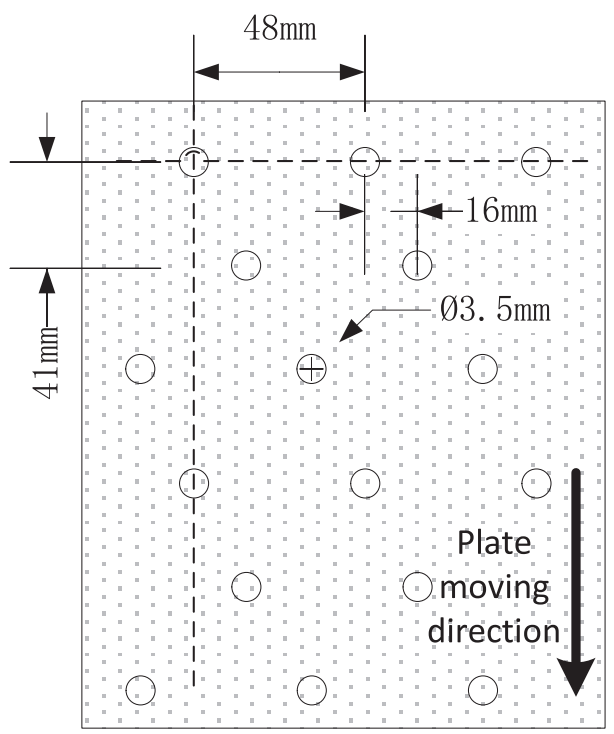

Fig. 2. Photo of cooling flow of UFC nozzles

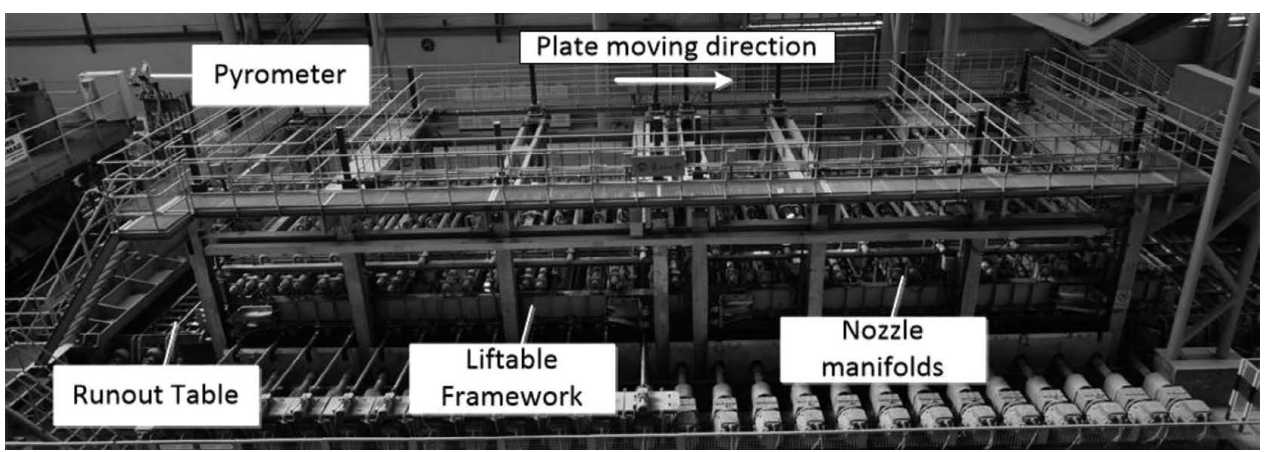

Fig. 1. Photo of the ultra-fast cooling system.

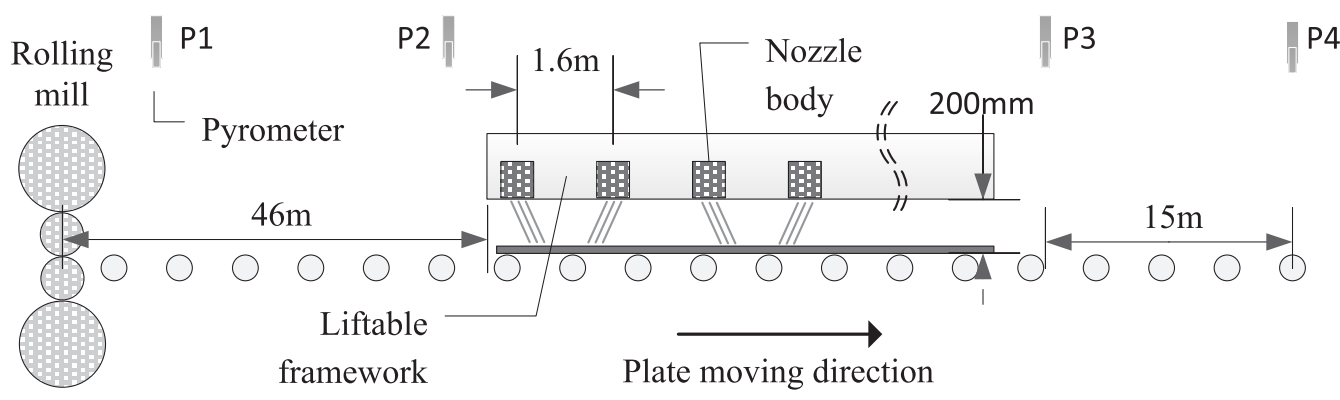

Fig. 3. The arrangements of the cooling system and pyrometers.

Table 1. Composition of steel plates (wt.\%).

\begin{tabular}{ccccccccccc}
\hline Steel & $\mathrm{C}$ & $\mathrm{Mn}$ & $\mathrm{Si}$ & $\mathrm{Cu}$ & $\mathrm{Cr}$ & $\mathrm{Ni}$ & $\mathrm{Mo}$ & $\mathrm{Ti}$ & $\mathrm{Nb}$ & $\mathrm{V}$ \\
\hline $\mathrm{Q} 345 \mathrm{~B}$ & 0.183 & 1.34 & 0.171 & 0.0167 & 0.049 & 0.038 & 0.004 & 0.003 & 0.01 & 0.005 \\
\hline
\end{tabular}


Table 2. Experimental conditions.

\begin{tabular}{|c|c|c|c|c|c|c|}
\hline case & $\begin{array}{c}\begin{array}{c}\text { volumetric } \\
\text { flux }\end{array} \\
1 / \mathrm{m}^{2} \mathrm{~s}\end{array}$ & $\begin{array}{c}\text { impinging } \\
\text { jet speed } \\
\mathrm{m} / \mathrm{s}\end{array}$ & $\begin{array}{c}\text { table } \\
\text { moving } \\
\text { speed } \\
\mathrm{m} / \mathrm{s}\end{array}$ & $\begin{array}{l}T_{w} \\
{ }^{\circ} \mathrm{C}\end{array}$ & $\begin{array}{c}\text { cooling } \\
\text { zone } \\
\text { length } \\
\text { m }\end{array}$ & $\begin{array}{c}\text { activated } \\
\text { nozzle } \\
\text { body }\end{array}$ \\
\hline $\mathrm{C} 1$ & 14.63 & 4.92 & 1.4 & 19.4 & 6.4 & 8 \\
\hline $\mathrm{C} 2$ & 19.51 & 6.56 & 1.4 & 19.4 & 6.4 & 8 \\
\hline $\mathrm{C} 3$ & 24.38 & 8.2 & 1.4 & 19.4 & 6.4 & 8 \\
\hline C4 & 29.26 & 9.84 & 1.4 & 19.4 & 6.4 & 8 \\
\hline $\mathrm{C} 5$ & 24.38 & 8.2 & 0.7 & 19.4 & 3.2 & 4 \\
\hline C6 & 34.14 & 11.48 & 0.7 & 19.4 & 3.2 & 4 \\
\hline
\end{tabular}

finished rolling temperature was $860 \pm 20^{\circ} \mathrm{C}$. In this study, 6 plates were manufactured using the identical parameters to minimize the effect of interference factors, such as oxide thickness of the plate, and the plate temperature. The corresponding experimental conditions are listed in Table 2.

\section{Numerical Study}

\subsection{Numerical Procedure}

Calculation domain and boundary conditions for the cooling process are presented in Fig. 4. The numerical calculation was carried out using ANSYS Fluent software version 15.0. The volume of fluid (VOF) model was adopted to calculate the flow field, and the reliable $k-\varepsilon$ model was used to calculate the turbulence. Each nozzle entrance was set to velocity input condition with water fraction of 1 , which meant that the nozzle was full of water. The nonnozzle part of the top surface was set to pressure outlet boundary condition of $0 \mathrm{MPa}$ and the back flow rate was $0 \mathrm{~m} / \mathrm{s}$. The governing equations of convection and diffusion terms were discretized using the second-order upwind scheme. The SIMPLE algorithm was employed to calculate the pressure. ${ }^{10)}$

\subsection{Determining Heat Transfer Coefficient}

The energy balance of plate cooling process is given by (1):

$$
-\rho \cdot \mathrm{c} \cdot \mathrm{s} \cdot \frac{\Delta T}{\Delta t}=\dot{q}_{i}+\dot{q}_{R}+\dot{q}_{\alpha}
$$

Where $\rho, \mathrm{c}$, and s are the density, specific heat capacity, and plate thickness, respectively. The enthalpy change for the plate was equal to the sum of heat transfer by the impinging jet $\dot{q}_{i}$, the heat flux by radiation $\dot{q}_{R}$ and convection $\dot{q}_{\alpha}$. And the phase transition latent heat was not taken into consideration in this calculation. A software based on finite element method (FEM) was developed to calculate $H T C_{a}$. The details of FEM can be found in the previous studies. ${ }^{12,13)}$ Considering the heterogeneous distribution of surface temperature on the plate and the relative low temperature in the peripheral region, the characteristic temperature for calculating the $H T C_{a}$ was according to the average temperature along the longitudinal direction. The deviation of after rolling temperature was within $25^{\circ} \mathrm{C}$.

The $H T C_{a}$ calculation process is shown in Fig. 5. The main strategy was to minimize the deviation of calculated temperature and measured temperature by pyrometer P4. In the calculation, the cooling condition and equalization time

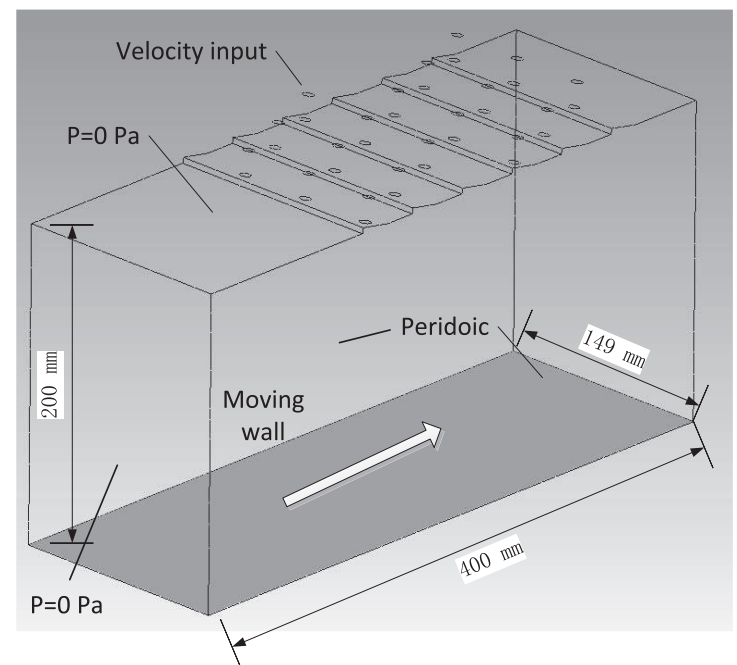

Fig. 4. Calculation domain and the associated boundary conditions.

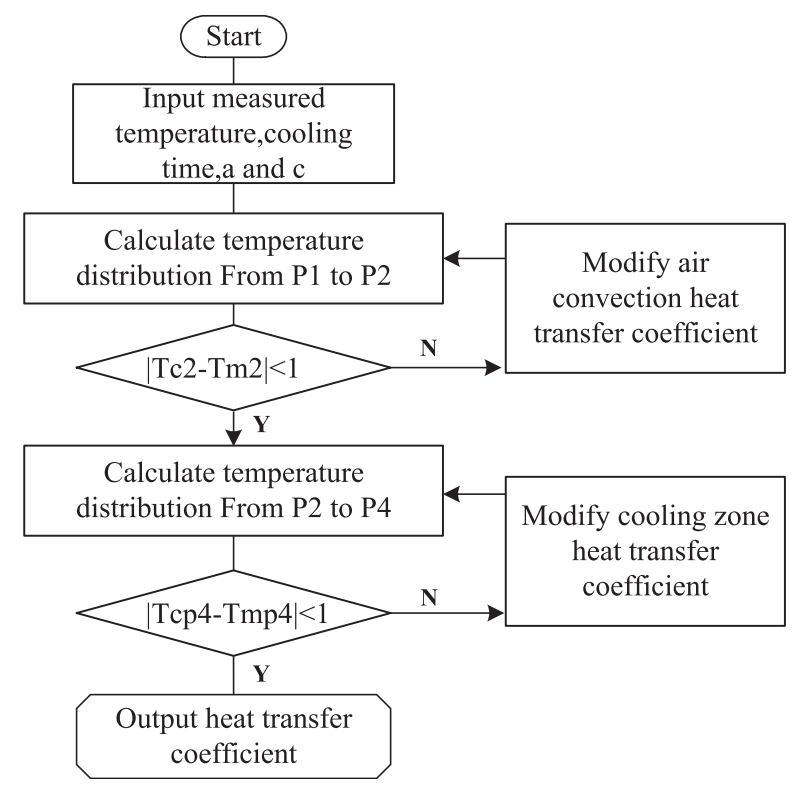

Fig. 5. Flow chart of average heat transfer coefficient calculation.

were identical to the actual manufacturing processes, where involved the convection and radiation. The judging criteria for the calculation were the absolute difference between the measured temperature and calculated temperature at P2 and $\mathrm{P} 4$, which located at the entrance of the cooling device and $15 \mathrm{~m}$ behind the exit, respectively.

\section{Result Analyses}

\subsection{Surface Flow Field}

The streamlines with $V_{i}=4.92 \mathrm{~m} / \mathrm{s}$, which are a family of curves calculated from the instantaneously tangent to the velocity vector of the flow, are displayed in Fig. 6. These streamlines ${ }^{14)}$ represented the directions that the fluid element would travel in at any point in time and provided a snapshot of some flow field characteristics. In the direction vertical to the plate, the speed decreased gradually. Additionally, the speed attenuated along the outside nozzles array direction, and the max attenuation was at row 4 . The inclination angle of the jet increased sharply in the condition of outside nozzles (nozzle 1,2) when the flow was close to the surface. The jet flow around row 4 was restricted by the 


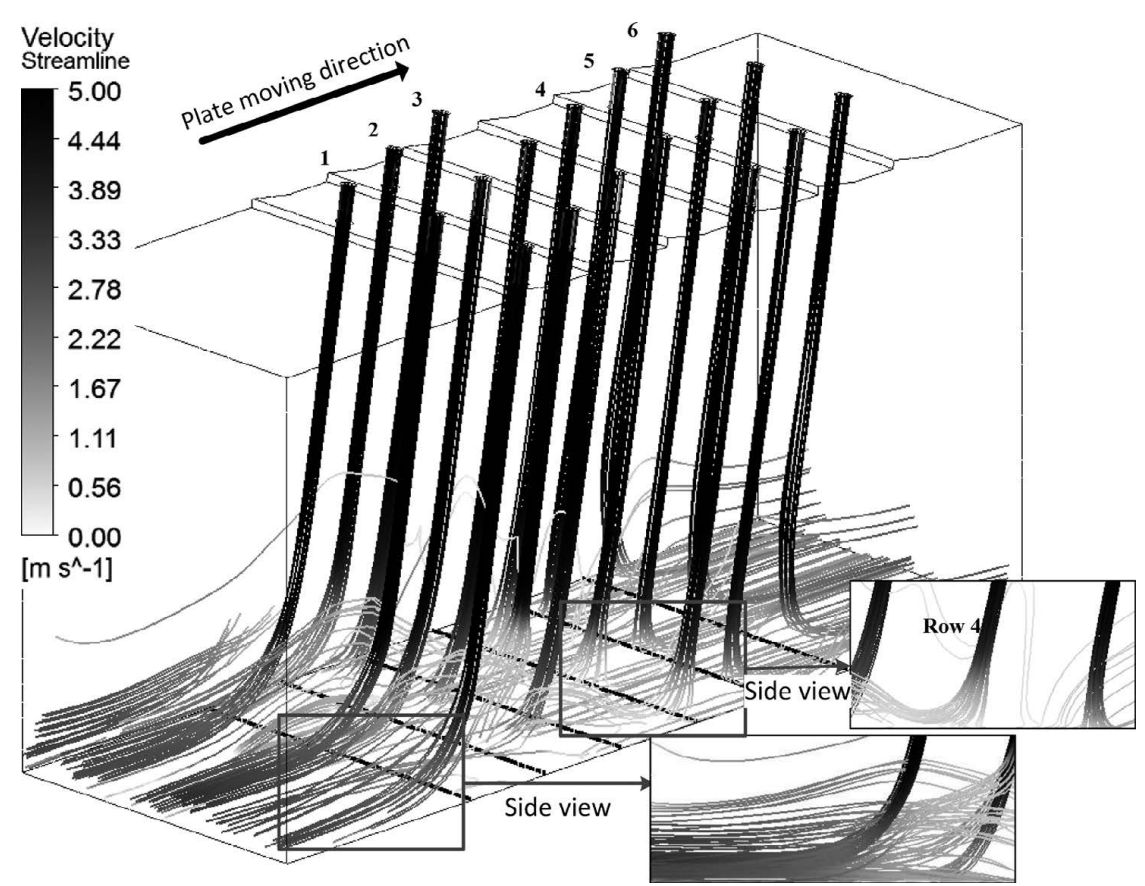

Fig. 6. Streamlines of the flow field with velocity demonstration when $V_{i}=4.92 \mathrm{~m} / \mathrm{s}$.

outward jets for the interference of surface flow and residual water on the moving surface. The obvious flow layer was near the exit boundary, and the flow velocity decreased with the height of flow.

The advantages offered by inclination jets were as follows: firstly, the slipped water became more ordered. Secondly, the orientation of flow was adjusted to reduce water residence time. With the help of water-hinder-roller and side-blow device, uniform cooling can be achieved. The water-hinder-roller, which installed about $20 \mathrm{~mm}$ above the plate surface, can scrape off the accumulated water higher than $20 \mathrm{~mm}$; moreover, the inclined side-blow device at the gap of nozzle manifolds, which impinged from the orthogonal direction of the plate moving, can also blow off the accumulated water under the impinging of side-blow device.

\subsection{Analysis of Surface Pressure}

Surface pressure is usually considered as the intensity of the jet impinged on the surface, and it increases with jet velocity. The single jet impinging experiments had already revealed that the higher flow velocity would result in higher pressure. $^{15,16)}$ Meanwhile, the proportion of nucleate boiling may also increase because of the strong bubble release ability at high parallel speed. The distribution of surface pressure with jet velocity is presented in Fig. 7. In Fig. 7, six dotted lines were the projection of nozzles along the inclination direction. It is clear that the increased jet velocity enhanced both the maximum pressure and its influenced area.

The surface flow states of the multiple jets impinged on the glass plate is presented in Fig. 8, the hexagonal influence regions of each single jet (marked blue in Figs. 7 and 8 ) were formed by the interaction of neighboring flows. The white boundary of the hexagonal influence area was consisted of flows between jets (shown in Fig. 8). During the cooling process, the maximum effective wetted area of each jet was the hexagonal influence area for the wetted regions would connect with each other with further expanding the

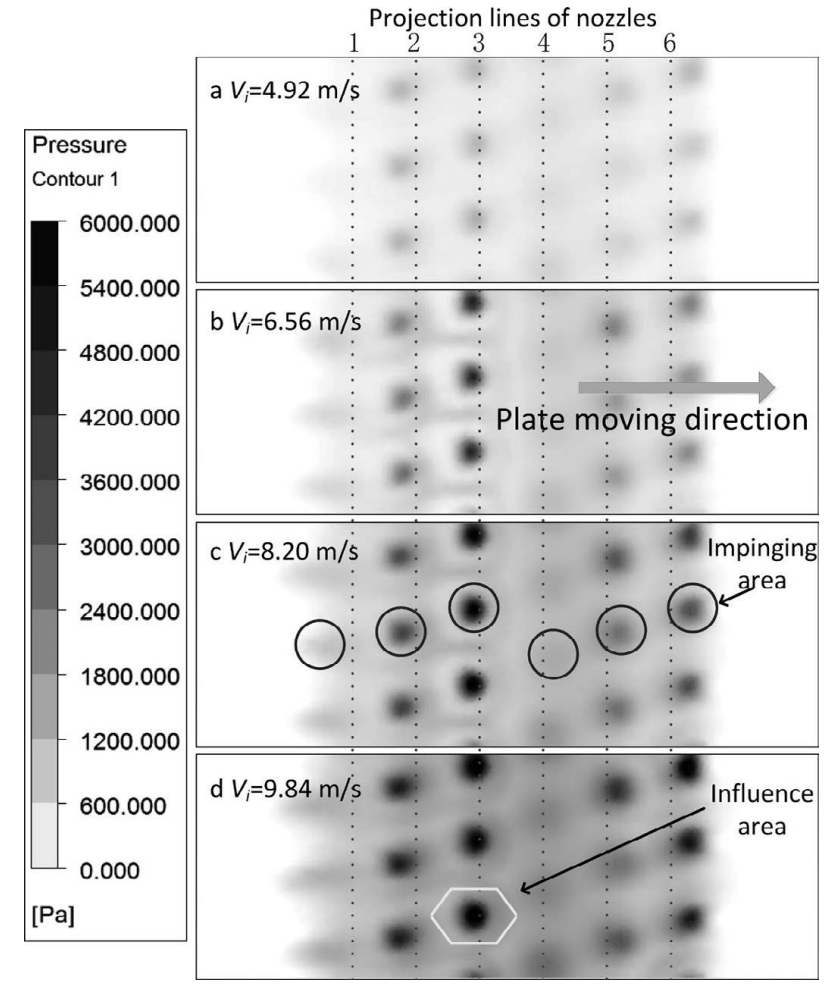

Fig. 7. Variation of surface pressure with $V_{i}$.

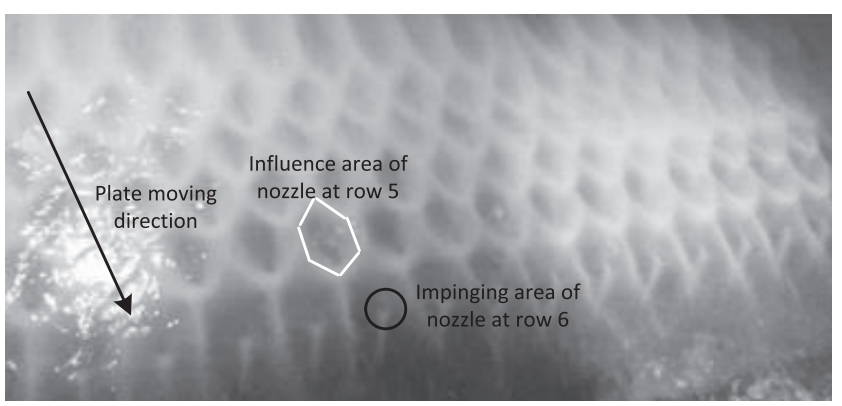

Fig. 8. The surface flow states of the multiple jets impinged on the glass plate. 
wetted area.

The average surface pressure of the impinging area can be considered as the intensity of impinging jet. Under multiple jets cooling, the wetted region still firstly appeared at the impinging point and then expanded gradually. Therefore, the average surface pressure in the impinging area played the most important role in expanding the wetted region. The average pressure, $P_{i}$ in a circled area (marked red in Figs. 7 and 8 , radius $15 \mathrm{~mm}$ ) which centered at the impinging point was calculated. $P_{i}$ of the nozzles from row 1 to row 6 were presented in Fig. 9. Although the trend of these curves was similar, the much more violent fluctuation of intensity with higher $V_{i}$ can be observed. Meanwhile, $P_{i}$ at each location increased monotonously with $V_{i}$ and was unaffected by the corresponding strengthed interference of surface flow field. What's more, the maximum pressure region lay in the nozzles of row 3 and the minimum pressure located in the impinging region of row 1 where the interference of parallel flow was apparent.

The whole plate surface would experience transient impingement for several times (from nozzle row 1 to 6 ) during the manufacturing process. Therefore, the average pressure along length direction, which was denoted as $\bar{P}_{i}$ by averaging $P_{i}$ from nozzle 1 to 6 , could better reflect the influence on $H T C_{a}$. As shown in Fig. 10, $\bar{P}_{i}$ almost increased linearly with $V_{i}$, and $\bar{P}_{i}$ increased 5.7 times when the $V_{i}$ increased 2.3 times. It is worth noting that the pressures in

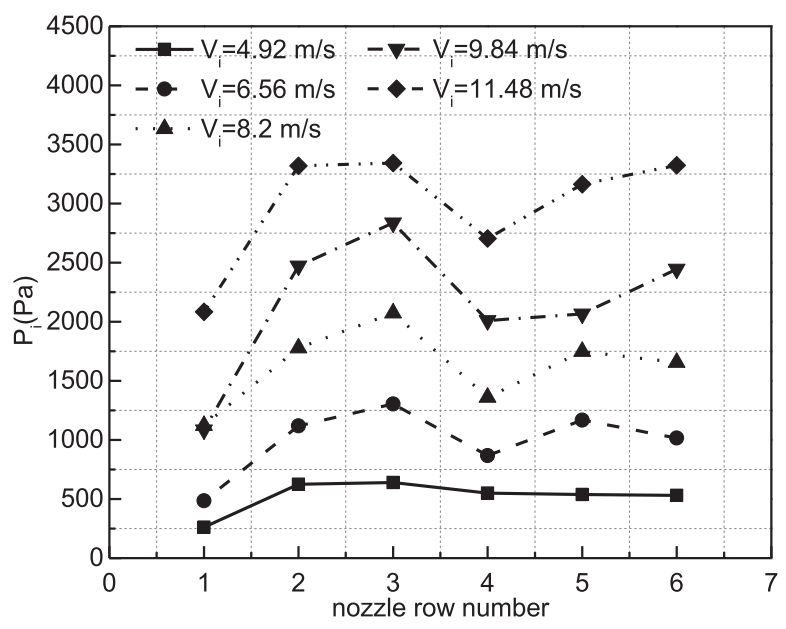

Fig. 9. Variation of $P_{i}$ with $V_{i}$ along length direction.

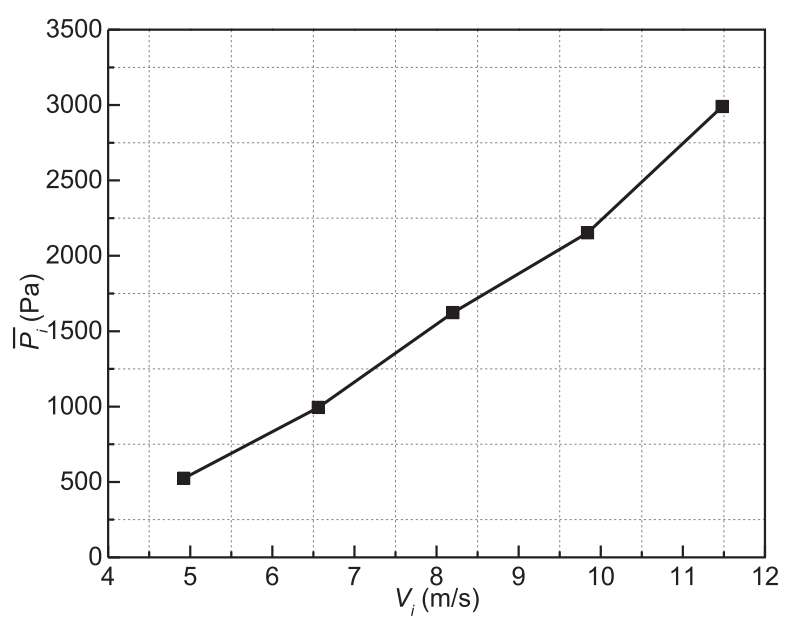

Fig. 10. Variation of $\bar{P}_{i}$ with $V_{i}$. the impinging area were not weakened in spite of the much more violent interaction of surface flow under higher jet velocity.

\subsection{Average Heat Transfer Coefficient}

In the industrial process, the accuracy of temperature control depends on many factors. Figure 11 shows the temperature change of plate with rolling time. It was hard to ensure that each plate experienced same air cooling time and rolling schedule, thus the finished rolling temperature of the plate was in the range of $857-871^{\circ} \mathrm{C}$. Pyrometer P1 was arranged behind rolling mill, $\mathrm{P} 2$ was at the entrance of cooling system, P3 was at the exit of the cooling system and P4 was arranged $15 \mathrm{~m}$ behind the exit of the cooling system. It should be noted that temperature equalization at the position of P4 may be difficult to achieve for lacking of time.

Figure 12 compares the calculated temperature and measured temperature, the cooling rates in the core and on the surface of the plate were similar during air cooling before water cooling. A dramatic decrease in temperature was observed when water impinged on the surface and afterward, the temperature abruptly rise again when the plate left water cooling region. The deviation in calculated surface temperature and the measured temperature was mainly caused by the hypothetical heat conductivity and

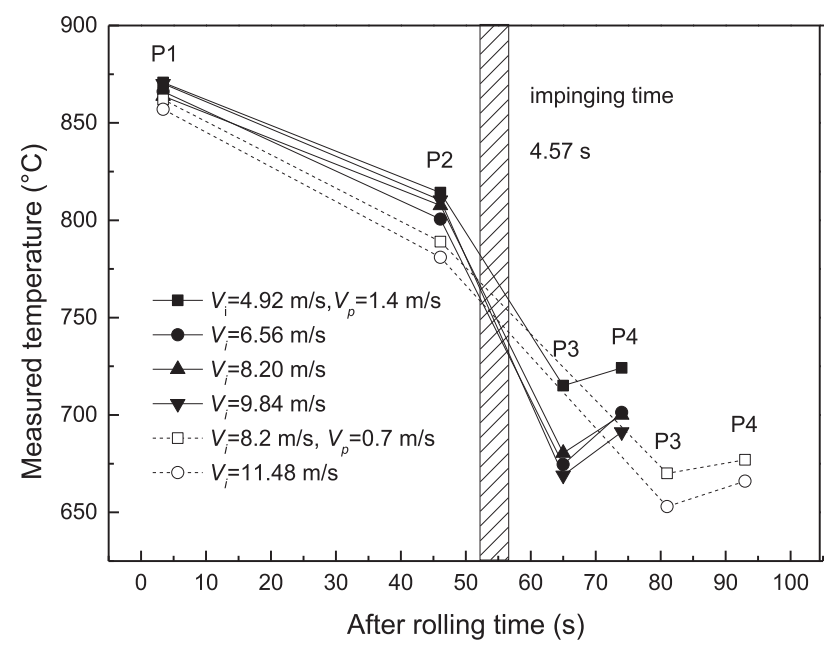

Fig. 11. Variation of the measured temperature with after rolling time at different $V_{i}$

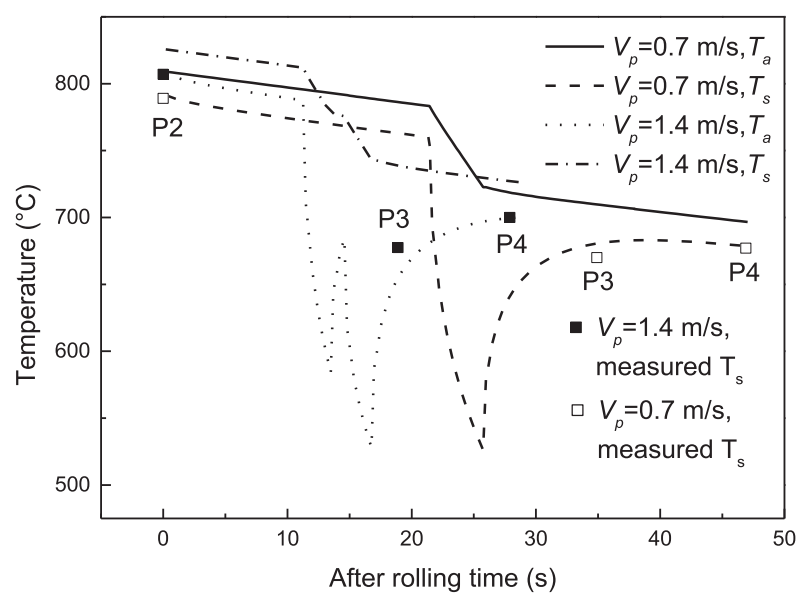

Fig. 12. The history of calculated temperature and measured temperature with different $V_{p}$. 
the uncertainty in HTC which varied with temperature. The small deviation demonstrated the good reliability of the calculation. The $H T C_{a}$ corresponded to the temperature range of $500-800^{\circ} \mathrm{C}$, and the relationship between $H T C$ and temperature were not studied here for the constraint of the measurement. 8 nozzle-manifolds were activated when $V_{P}=1.4 \mathrm{~m} / \mathrm{s}$, and a spare air cooling region existed between the cooling regions. This is the reason the surface temperature at $V_{P}=1.4 \mathrm{~m} / \mathrm{s}$ showed a promotion during water cooling. To maintain same cooling time in the case $V_{P}=0.7 \mathrm{~m} / \mathrm{s}$, the number of the nozzle- manifolds was reduced by half.

During the impinging cooling process, the small black circle appearing in the stagnant zone is referred as wetted region, which is in correlation with the strongest heat transfer. ${ }^{17)}$ Moreover, the wetted region would keep expanding as the cooling goes on. Under moving condition, the most important factor that influenced $H T C_{a}^{3,6,18-21)}$ was the wetted region expanding speed (WRES), which was substantially influenced by the $P_{i}$ in this study. In addition, the other influenced $H T C_{a}$ factors included the initial plate temperature and water temperature, which were almost kept constant in the experiment.

As shown in Fig. 13, when $\bar{P}_{i}$ was in the range of 525-2 $989 \mathrm{~Pa}$ (volumetric flux 14.63-34.14 1/ $\mathrm{mim}^{2}$ ), $H T C_{a}$ increased with $\bar{P}_{i}$, whereas $E_{v i}$ showed an inverted trend. The sharpest growth of $H T C_{a}$ (increased 22.1\%) occurred when $\bar{P}_{i}$ improved from $525 \mathrm{~Pa}$ to $993 \mathrm{~Pa}$. Then, growth of $H T C_{a}$ became flat with further increasing $\bar{P}_{i}$. When $\bar{P}_{i}$ increased from $1623 \mathrm{~Pa}$ to $2989 \mathrm{~Pa}$ (increased 84.2\%) at $V_{p}=0.7$ $\mathrm{m} / \mathrm{s}$, the $H T C_{a}$ increased by only $8.4 \%$ (from $3281 \mathrm{~W} / \mathrm{m}^{2} \mathrm{~K}$ to $3555 \mathrm{~W} / \mathrm{m}^{2} \mathrm{~K}$ ). The reason for the slow growth of $H T C_{a}$ and the decreasing $E_{v i}$ was the hydrodynamics feature of the impinging jet, after which the flow was partially converted into the parallel flow. And the largely increased water flow above the thermal boundary layer, where the effective heat transfer happened. ${ }^{22)}$

Both of $H T C_{a}$ and $E_{v i}$ showed lower values in $V_{p}=0.7 \mathrm{~m} / \mathrm{s}$ than in $V_{p}=1.4 \mathrm{~m} / \mathrm{s}$, and the difference of $H T C_{a}$ between distinct $V_{p}$ was $7.4 \%$ when $V_{i}$ was $8.2 \mathrm{~m} / \mathrm{s}$. Chen ${ }^{23,24)}$ also found the similar results and concluded that the surface motion would increase the cooling efficiency of roll and strip cooling. A reasonable explanation was that more cooling cycles were executed in the case of $V_{p}=1.4 \mathrm{~m} / \mathrm{s}$ than in the case of $V_{p}=0.7 \mathrm{~m} / \mathrm{s}$ because the cooling time is the same in both cases and the cooling length of the

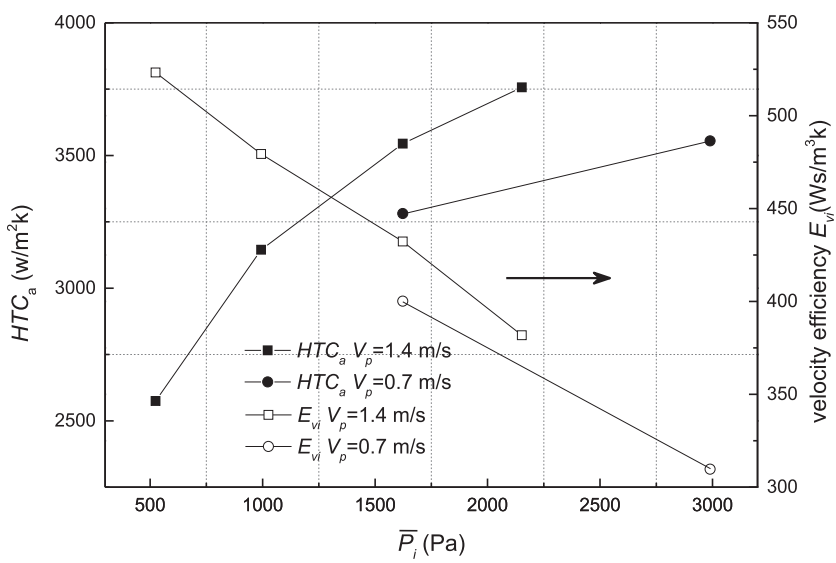

Fig. 13. Variation of $H T C_{a}$ and $E_{v i}$ with $\bar{P}_{i}$. case of $V_{p}=0.7 \mathrm{~m} / \mathrm{s}$ is half of the case of $V_{p}=1.4 \mathrm{~m} / \mathrm{s}$. The shortened impinging time (versus more cooling cycles in the case of $V_{p}=1.4 \mathrm{~m} / \mathrm{s}$ ) would result in a slow temperature drop and follow by a quick temperature rise on the plate surface. Eventually, a higher surface temperature would be found before another impingement. While other studies ${ }^{18)}$ claimed that the maximum heat flux increased with the initial temperature. Because of lack of identically sized plate in the experiment, the $H T C_{a}$ at $V_{i}=11.48 \mathrm{~m} / \mathrm{s}$ was unavailable. It is hard for the wetted region to reach the maximum when the $V_{p}$ is relatively fast because the impinging time is shortened. Therefore, in the higher $P_{i}$ zone, more efficient cooling performance would be accomplished when the plate moving speed is faster.

The brief comparison about the relationship between $H T C_{a}$ and $V_{i}$ in this and previous works is given Fig. 14. Due to the linear relation of $V_{i}$ and $P_{i}$ (shown in Fig. 10), the $V_{i}$ was used as the abscissa for better understanding. The initial surface temperature of $\sim 890^{\circ} \mathrm{C}$ in karwa's result ${ }^{25)}$ was higher than in this paper. Corresponding with the stronger boiling driving force, the higher initial cooling temperature had higher heat flux. The water temperature was $\sim 25.5^{\circ} \mathrm{C}$; the water jet speed was $2.5,5.1,7.5,9.75 \mathrm{~m} / \mathrm{s}$, respectively. With the nozzle diameter of $3 \mathrm{~mm}$, the average heat transfer coefficients were calculated in the temperature range of 500 to $900^{\circ} \mathrm{C}$. Compared with experimental conditions in this study, the differences of water temperature and nozzle diameter are small, and would hardly affect the heat transfer process obviously. Apparently, the $H T C_{a}$ in this work is lower relatively to the previous works. This can be attributed to that because of the plate is moving, the entire cooling area was taken in calculating the $H T C_{a}$, including the area with lower HTC (HTC usually decreases with the increasing distance to the impinging point). However, the results in other works were based on a specific point which was close to the impinging point. In karwa's result, ${ }^{25)}$ at impinging point $(\mathrm{r}=0)$, the $H T C_{a}$ decreased with the increased $V_{i}$, proving the increased $V_{i}$ ( $P_{i}$ also increased at the same time) did not substantially elevating the $H T C$ at the impinging point. At point $\mathrm{r}=8 \mathrm{~mm}$, the curve of $H T C_{a}$ was similar to the result of this work, where the effect of $V_{i}$ on improving the $H T C_{a}$ attenuated with increasing $V_{i}$. Meanwhile, the $H T C_{a}$ increased just by $19.3 \%$ when $V_{i}$ increased from 5.1 to $7.5 \mathrm{~m} / \mathrm{s}$, whereas $H T C_{a}$ increased $25.0 \%$ in this work. In chitranjan's work, ${ }^{18)}$ the correlation of maximum heat flux

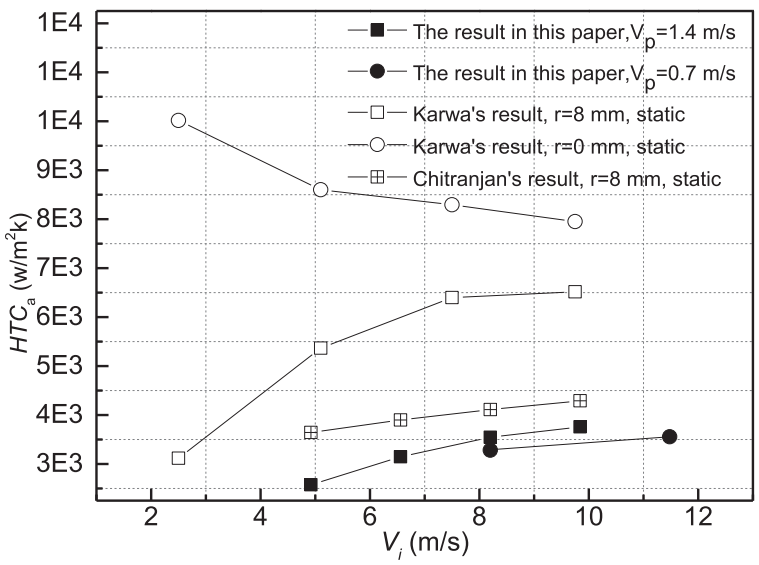

Fig. 14. Comparison of experimental data with other works. 
was derived from the initial surface temperature of $\sim 800^{\circ} \mathrm{C}$ with a nozzle diameter of $2.5 \mathrm{~mm}$ and water temperature of $22^{\circ} \mathrm{C}$. Base on the correlation, under the assumption that the heat flux reached the maximum at $T_{s}=550^{\circ} \mathrm{C}$, the corresponding heat transfer coefficient was calculated under the same experimental conditions as in this study. The curve of corresponding HTC (nearly two times $H T C_{a}$ in the cooling range $500-800^{\circ} \mathrm{C}$ ) at point $\mathrm{r}=8 \mathrm{~mm}$ also behave analogously to this study.

Most of the available numeral studies ${ }^{26-29)}$ of turbulent flow and heat transfer mainly focused on the surface heat conduction rather than the boiling process for the complicated boundary condition. As a result, the existing experiment results still cannot be used to predict the temperature field of the plate during the online cooling process. Also, the previous research emphasized on the fixed single impinging jet, which was quite different from this study. In this work, the relationship of $V_{i}$ and $P_{i}$ was studied. The influence of $\bar{P}_{i}$ and $V_{p}$ on the $H T C_{a}$ and $E_{v i}$ during the online production were analyzed quantitatively, and the $H T C_{a}$ were finally obtained. The numerical analysis of the flow states was used to analyze the causes of the decreased $E_{v i}$. Moreover, the obtained experimental data were helpful to predict the plate temperature field in the actual manufacturing condition and provided insight into the development of high-performance and high-efficiency cooling device.

\section{Conclusions}

(1) The flow field studies were carried out in an industrial cooling device. The results revealed that the $P_{i}$ in the impinging area increased near linearly with increasing $V_{i}$.

(2) When $\bar{P}_{i}$ was in the range of $529 \mathrm{~Pa}$ to $2989 \mathrm{~Pa}$ (volumetric flux 14.63-34.14 1/ $\mathrm{minm}^{2}$ ), the $H T C_{a}$ increased with $\bar{P}_{i}$, but the increase rate and $E_{v i}$ declined. When $\bar{P}_{i}$ increased from $1623 \mathrm{~Pa}$ to $2989 \mathrm{~Pa}$ at $V_{p}=0.7 \mathrm{~m} / \mathrm{s}$, the increased amplitude of $H T C_{a}$ was only $8.4 \%$. Therefore, the flow speed should be optimized to accomplish the higher $E_{v i}$.

(3) In the same cooling time, $H T C_{a}$ showed lower values in $V_{p}=0.7 \mathrm{~m} / \mathrm{s}$ than in $V_{p}=1.4 \mathrm{~m} / \mathrm{s}$, the difference of $H T C_{a}$ between distinct $V_{p}$ was $7.4 \%$ when $V_{i}=8.2 \mathrm{~m} / \mathrm{s}$. Increasing $V_{p}$ was also beneficial to improve the $H T C_{a}$.

(4) $H T C_{a}$ under different jet velocities was obtained, and this data can be utilized to predict the cooling rate and microstructure of the steel product.

The cooling ability and efficiency in practice are still far below the theoretical values. Thus, it is valuable to develop the plate cooling process in the steel industry. Further work on the temperature and flow field under multiple nozzles with different arrangements should be carried out to decrease water consumption as well as increase cooling ability, which would be beneficial to the manufacturer of high-quality steel.

\section{Acknowledgements}

This work was supported by the National Science Foundation of China (Grant No. 51404058 and 51234002), and the Fundamental Research Funds for the Central Universities (N150704005).

Thanks to S. J. Liao, H. B. Guo of China Nanjing Iron
\& Steel Group Corp. (NISCO) for their help to offer the experimental plate and cooling system.

\section{Nomenclature}

$H T C_{a}$ : average heat transfer coefficient $\left(\mathrm{W} / \mathrm{m}^{2} \mathrm{~K}\right)$

$V_{i}$ : nozzle impinging speed $(\mathrm{m} / \mathrm{s})$

$V_{p}$ : plate moving speed $(\mathrm{m} / \mathrm{s})$

$T_{s}$ : plate surface temperature $\left({ }^{\circ} \mathrm{C}\right)$

$T_{a}$ : plate average temperature $\left({ }^{\circ} \mathrm{C}\right)$

$T_{w}$ : cooling water temperature $\left({ }^{\circ} \mathrm{C}\right)$

$T_{c 2}$ : calculated temperature at location of pyrometer 2 $\left({ }^{\circ} \mathrm{C}\right)$

$T_{m 2}$ : measured temperature at location of pyrometer 2 $\left({ }^{\circ} \mathrm{C}\right)$

$E_{v i}: \quad H T C_{a} / V_{i}$ the heat transfer effectiveness of nozzle impinging speed $\left(\mathrm{Ws} / \mathrm{m}^{3} \mathrm{~K}\right)$

$P_{i}$ : average pressure in the impinging region $(\mathrm{Pa})$

$\bar{P}_{i}: \quad$ average pressure of $P_{i}$ from nozzle 1 to $6(\mathrm{~Pa})$

$r$ : the distance to the impinging point $(\mathrm{mm})$

\section{REFERENCES}

1) D. A. Zumbrunnen, F. P. Incropera and R. A. Viskanta: Heat Mass Transf., 27 (1992), 311.

2) D. A. Zumbrunnen, R. A. Viskanta and F. P. Incropera: ASME J. Heat Transf., 111 (1989), 760.

3) A. K. Mozumder and P. L. Woodfield: Int. J. Heat Mass Transf., 50 (2007), 1559.

4) P. L. Woodfield and M. Monde: Int. J. Heat Mass Transf., 48 (2005), 2032.

5) N. Karwa, G. R. Tatiana, P. Stephan and T. Cameron: Exp. Therm. Fluid Sci., 7 (2011), 1435.

6) N. Karwa, L. Schmidt and P. Stephan: Int. J. Heat Mass Transf., 55 (2012), 3677.

7) H. Robidou, H. Auracher, P. Gardin and M. Lebouché: Exp. Therm. Fluid Sci., 26 (2002), 123.

8) A. K. Mozumder, Y. Mitsutake and M. Monde: J. Energy Power Eng., 7 (2013), 411.

9) M. Gradeck, A. Kouachi, A. Dani, D. Arnoult and J. L. Borean: Exp. Therm. Fluid Sci, 30 (2006), 193.

10) M. J. Cho, B. G. Thomas and P. J. Lee: Metall. Mater. Trans. B, 39 (2008), 593.

11) B. P. E. Dano, J. A. Liburdy and K. Kanokjaruviji: Int. J. Heat Mass Transf., 48 (2005), 691.

12) D. Celentano, E. Orate and S. Oller: Int. J. Num. Methods. Eng., 37 (1994), 3441

13) A. K. Nallathambi and E. Specht: J. Mater. Process. Technol., 209 (2009), 5325.

14) G. K. Batchelor: Introduction to Fluid Dynamics. Cambridge University Press, Cambridge, (2000), 72.

15) M. Monde, K. Kitajima, T. Inoue and Y. Mitsutake: ASME J. Heat Transf., 7 (1994), 515.

16) B. Wang, Q. Xie, Z. Wang and G. Wang: J. Cent. South Univ., 20 (2013), 2960.

17) A. K. Mozumder, M. Monder and P. L. Woodfield: Int. J. Heat Mass Transf., 48 (2005), 5395.

18) C. Agrawal, R. Kumar, A. Gupta and B. Chatterjee: Int. J. Heat Mass Transf., 55 (2012), 4772.

19) N. L. Chester, M. A. Wells and V. Prodanovic: J. Heat Transf., 134 (2012), 122201.

20) N. Karwa, L. Schmidt and P. Stephan: Int. J. Heat Mass Transf., 55 (2012), 3677.

21) D. H. Wolf, F. P. Incropera and R. Viskanta: Int. J. Heat Mass Transf., 39 (1996), 1395

22) N. Karwa, T. Gambaryan-Roisman, P. Stephan and C. Tropea: Int. J. Therm. Sci., 6 (2011), 993.

$23)$ S. J. Chen, J. Kothari and A. A. Tseng: Exp. Therm. Fluid Sci., 4 (1991), 343.

24) S. J. Chen and A. A. Tseng: Int. J. Heat Fluid Flow., 13 (1992), 358.

$25)$ N. Karwa: Ph D. thesis, Technical University of Darmstadt, (2012).

26) T. S. Park and H. J. Sung: Int. J. Heat Fluid Flow., 22 (2001), 10.

27) M. Behnia, S. Parneix and P. A. Durbin: Int. J. Heat Fluid Flow., 20 (1999), 1.

28) H. Chattopadhyay and S. K. Saha: Int. J. Heat Fluid Flow., 24 (2003), 685.

29) M. Behnia, S. Parneix and P. A. Durbin: Int. J. Heat Mass Transf., 41 (1998), 1845. 